\title{
Pulmonary heart valve replacement using stabilized acellular xenogeneic scaffolds; effects of seeding with autologous stem cells
}

\section{Inlocuiri valvulare pulmonare folosind scaffolduri xenogenice acelulare stabilizate; efectul insamantarii cu celule stem autologe}

\author{
Marius Mihai Harpa ${ }^{1}$, Ionela Movileanu ${ }^{1}$, Leslie Neil Sierad ${ }^{2}$, Ovidiu Simion \\ Cotoi $^{1}$, Horatiu Suciu ${ }^{3}$, Carmen Sircuta ${ }^{3}$, Terezia Preda ${ }^{1}$, Dan Nistor ${ }^{3}$, Klara \\ Branzaniuc $^{1}$, Radu Deac ${ }^{1}$, Michael Dandel ${ }^{1}$, Simona Gurzu ${ }^{1}$, Lucian Harceaga ${ }^{1}$, \\ Peter Olah ${ }^{1}$, Agneta Simionescu $^{4}$, Dan Simionescu ${ }^{5 *}$
}

1. Tissue Engineering and Regenerative Medicine Laboratory, University of Medicine and Pharmacy, Targu Mures, Romania; 2. Aptus LLC, Clemson, SC, USA; 3. Emergency Institute for Cardiovascular Diseases and Transplantation, Cardiovascular Surgery, Targu Mures, Romania; 4. Cardiovascular Tissue Engineering and Regenerative Medicine Laboratory, Clemson University, SC, USA; 5. Clemson University Clemson, SC, USA

\begin{abstract}
Background: We hypothesized that an ideal heart valve replacement would be acellular valve root scaffolds seeded with autologous stem cells. To test this hypothesis, we prepared porcine acellular pulmonary valves, seeded them with autologous adipose derived stem cells (ADSCS) and implanted them in sheep and compared them to acellular valves.

Methods: Fresh porcine pulmonary valve roots were decellularized with detergents and enzymes. ADSCs were isolated from subdermal fat and injected within the acellular cusps. Valves were then implanted in an extra-anatomic pulmonary position as RV to PA shunts: Group A $(n=6)$ consisted of acellular valves and Group B $(n=6)$ of

autologous stem cell-seeded acellular xenografts. Sheep were followed up for 6 months by echocardiography and histologic analysis was performed on explanted valves.

Results: Early evolution was favorable for both groups. All Group A animals had physiologic growth without any signs of heart failure and leaflets were found with preserved structure and mobility, lacking signs of thrombi, inflammation or calcification. Group B sheep however expressed signs of right ventricle failure starting at one month, accompanied by progressive regurgitation and right ventricle dilatation, and the leaflets were found covered with host tissue. No cells were found in any Group A or B explants.
\end{abstract}

*Corresponding author: Dan Simionescu, Clemson University, Clemson, SC, USA, e-mail: dsimion@clemson.edu 
Conclusions: Acellular stabilized xenogeneic pulmonary valves are reliable, stable,non-immunogenic, non-thrombogenic and non-calcifying scaffolds with excellent hemodynamics. Seeding these scaffolds with autologous ADSCs was not conducive to tissue regeneration. Studies aimed at understanding these novel observations and further harnessing the potential of stem cells are ongoing.

Keywords: scaffolds, heart valves, stem cells, implantation, animal model

\section{Rezumat}

Introducere: Am emis ipoteza ca un inlocuitor valvular ideal ar putea $f$ construit din radacini valvulare acelulare însămânate cu celule stem autologe. Pentru a testa ipoteza, am pregătit valve pulmonare porcine acelulare, le-am insamantat cu celule stem obtinute din tesut adipos (ADSCs) autolog si le-am implantat in oi, comparand rezultatele cu valve acelulare.

Metode: radacini de valve pulmonare porcine au fost decelularizate cu detergeni si enzime. ADSCs au fost izolate din grasimea subdermala si injectate in cuspisuri. Valvele au fost apoi implantate intr-o poziie extraanatomică ca sunt pulmonar VD la AP: Grupa A $(n=6)$ a constat din valve acelulare de control iar Grupa B $(n=6)$ au fost implantate $\mathrm{cu}$ valve insamantate cu ADSCs autologe. Oile au fost urmarite timp de 6 luni prin ecocardiografie iar dupa explantare valvele au fost analizate histologic.

Rezultate: Evolutia timpurie a fost pozitiva pentru ambele grupuri. Toate animalele din Grupa A au avut o crestere fiziologica normala fără semne de insuficientă cardiacă iar valvele au fost gasite cu structura si mobilitatea conservate, lipsite de semne de trombogeneza, inflamatie sau calcificare. Oile din Grupa B au dat semne de insuficienta a ventriculului drept începând de la o luna post-operator, însotita de regurgitare progresivă si dilatarea ventriculului drept, precum si acoperirea cu tesut gazdă a cuspisurilor. Nici o celula infiltrata sau insamantata nu a fost găsita în explantele din Grupa A sau B.

Concluzii: valvele pulmonare acelulare xenogene sunt stabile, non-imunogenice, non-trombogenice, cu hemodinamica excelenta si nu calcifica. Insămânarea acestora cu ADSCs autologe nu a fost propice pentru regenerarea tesutului. Studii care vizeaza intelegerea acestor fenomene noi si în exploatarea potentialului celulelor stem sunt in curs de desfasurare.

Cuvinte cheie: scaffolduri, valve cardiace, celule stem, implantare, model animal

Received: 12 $2^{\text {nd }}$ October 2015; Accepted: $16^{\text {th }}$ November 2015; Published: $1^{\text {st }}$ December 2015

\section{Introduction}

Since the first aortic valve xenograft implantation performed by Duran and Gunning in 1964 (1), constant progress has been made in order to obtain the perfect heart valve substitute. The current alternatives are either mechanical or biological valves, both of which have limited life spans and are associated with bleeding risks (mechanical valves), or degeneration and calcification (biological prosthesis) (2). Regenerative medicine aims to create living heart valves which would overcome the shortcomings of current alternatives. An ideal tissue engineered heart valve (TEHV) should encompass several characteristics: good hemodynamics, appropriate valve geometry, high durability, non-immunoge- nicity, non-inflammatory, non-thrombogenic and non-calcifying $(1,3)$. Additionally, for young patients, it should have the ability to grow and adapt with the patient's somatic growth (2, 4-6).

According to the accepted paradigm, the two main TEHV components are the template, or scaffold and the cells (7). The scaffold, either biologic or synthetic, should provide an adequate support for cell attachment and an environment for cells which can remodel the scaffold as a response to physiological stimuli. The cells used in TEHV should be easy obtainable, preferably from autologous sources and should have good expandability in vitro. Once seeded within the scaffolds, these will offer the valve viability, growth potential and remodeling capacity. 
Cell-seeded structures can then be introduced in a bioreactor, which allows different modes of stimulation and mechanical preconditioning (8), or alternatively, can directly be implanted for in vivo conditioning and maturation (3).

Evaluation of TEHV in vivo is typically performed in an animal model which resembles the physiologic and hemodynamic human characteristics. The gold standard for heart valve in vivo testing is considered the ovine model (9). In vivo periodical functional examination and histological assessment of the explants should be assessed at the follow-up end-point.

The objective of our study was to compare the in vivo behavior of non-seeded porcine acellular pulmonary valves with those seeded with autologous adipose derived stem cells (ADSCs) implanted in sheep. Valve-derived scaffolds are preferred because of easy accessibility, outstanding hemodynamic properties and the preservation of biological "niches" after decellularization (10-12). We also treat acellular scaffolds with penta-galloyl glucose (PGG) for tissue stabilization, to prevent premature scaffold degradation and to reduce calcification (13-15). We chose ADSCs because they are easy to obtain in large numbers and because of their plasticity and ability to differentiate into valve cells $(7,16)$. The expectation for the stem cells was to differentiate into interstitial valvular cells in vivo and to provide viability and matrix remodeling before extracellular matrix deterioration.

\section{Materials and methods}

\section{Acellular scaffolds}

Fresh porcine hearts were obtained from a local abattoir and transported to the laboratory on ice. Pulmonary roots were dissected and decellularized by immersion in glass containers on an orbital shaker using a ratio of $100 \mathrm{ml}$ solution / root. Decellularization steps consisted of incubation in $0.02 \%$ azide for 24 hours at $22^{\circ} \mathrm{C}$, loos- ening of extracellular matrix and initialization of cell removal $\left(0.05 \mathrm{M} \mathrm{NaOH}\right.$ for 1 hours at $\left.22^{\circ} \mathrm{C}\right)$, detergents $(0.05 \%$ sodium dodecyl sulfate, $0.5 \%$ Triton X-100, 0.5\% Na-Deoxycholate, and $0.2 \%$ EDTA in $10 \mathrm{mM}$ TRIS, $\mathrm{pH}$ 7.5) for 7 days at at $22^{\circ} \mathrm{C}$, with fresh solution changed daily. After rinsing, removal of nucleic acids was performed by incubation in $360 \mathrm{mU} / \mathrm{mL}$ deoxyribonuclease and $360 \mathrm{mU} / \mathrm{mL}$ ribonuclease in $5 \mathrm{mM} \mathrm{MgCl}_{2}$ in PBS for 1 day at $37^{\circ} \mathrm{C}$. To reduce bio-burden, each extraction step was preceded by a 20 minute $70 \%$ ethanol treatment and rinsing with sterile PBS. Finally the roots were incubated in $70 \%$ ethanol for 3 hours at $22^{\circ} \mathrm{C}$ and sterilized in $0.1 \%$ peracetic acid in PBS, $\mathrm{pH} 7.4$ for 2 hours at $22^{\circ} \mathrm{C}$. To stabilize the valve extracellular matrix, the acellular roots were treated with sterile $0.1 \%$ penta galloyl glucose (PGG) in 20\% isopropanol, an elastin-binding polyphenol (10) followed by a rapid glutaraldehyde treatment and complete neutralization with glycine to stabilize collagen (17). Acellular bovine pericardium, also stabilized with PGG, and used for mounting the valves within the conduit, was prepared as described before (18).

\section{Scaffold evaluation}

For histology, samples collected from fresh and decellularized pulmonary cusps and root tissues were fixed in $10 \%$ formalin, embedded in paraffin, sectioned at $5 \mu \mathrm{m}$ and stained with DAPI for nuclei and Hematoxylin \& Eosin (H\&E) for general structure. DNA was extracted and purified from tissue samples $(n=5)$ using the DN-easy Blood \& Tissue Kit (Qiagen) before analysis by Ethidium Bromide agarose gel electrophoresis (Figure 1).

\section{Valvular conduit manufacture}

In order to avoid cardio-pulmonary bypass risks, tissue engineered pulmonary valves were implanted in an extra-anatomic position between the right ventricle outflow tract and the pulmo- 

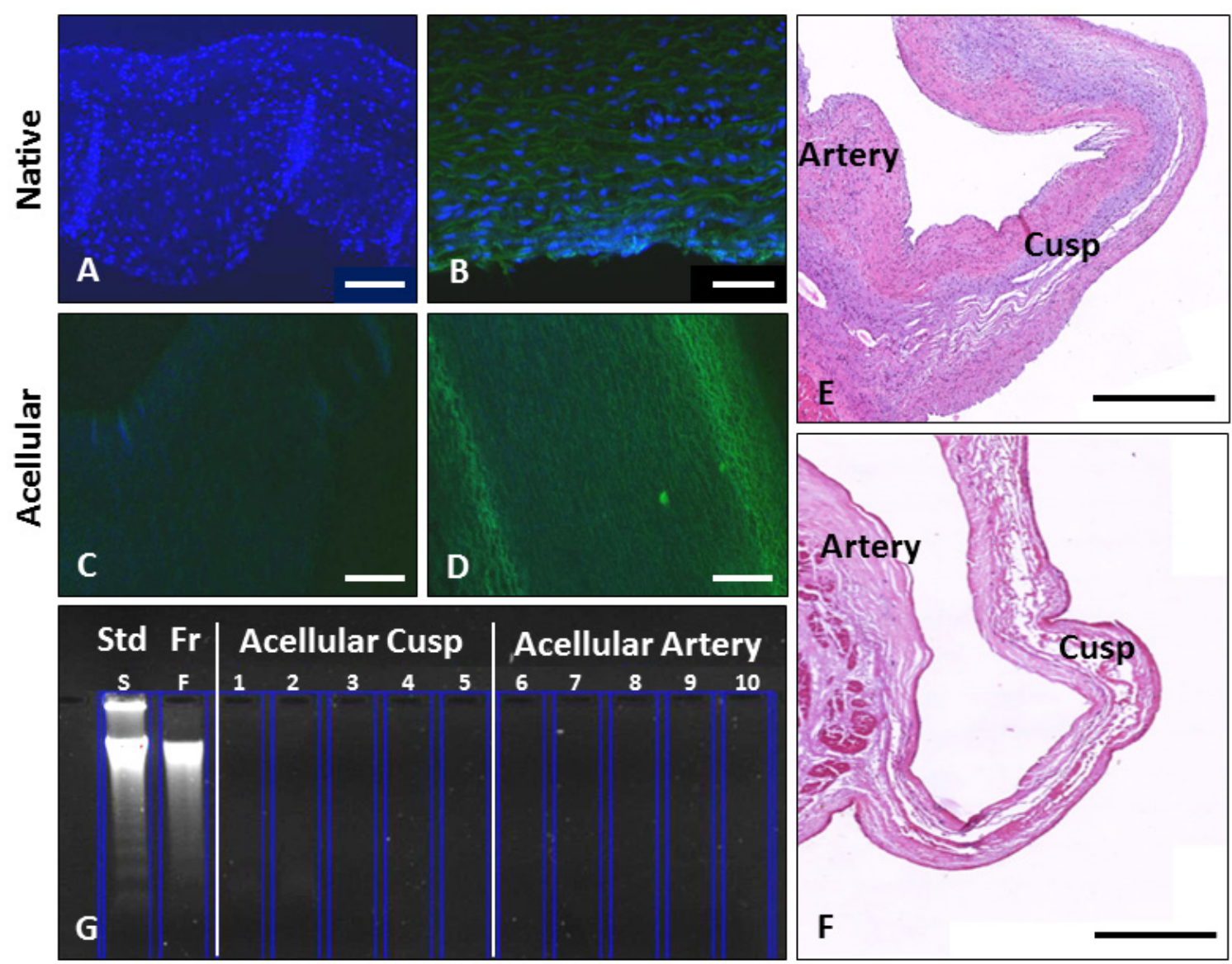

Figure 1. Validation of decellularization procedure. A-D, representative images of DAPI nuclear staining (blue) overlaid with elastin auto-fluorescence (green) of fresh native porcine pulmonary cusp (A) and artery

(B) and of decellularized cusp (C) and artery (D). E, F, representative low magnification images of H\&E stained native pulmonary roots before (E) and after (F) decellularization. G, ethidium bromide agarose gel electrophoresis of DNA extracted and purified from fresh pulmonary ( $\mathrm{Fr}$ ) and decellularized cusps and arteries $(\mathrm{n}=5$ lanes each); results were compared to a genomic DNA standard (Std). Scale bars in A-D are 100 um and in E, F 500 um.

nary artery, on the beating heart. For this purpose, we first created a valvular conduit by placing the pulmonary valve in a decellularized bovine pericardium tube, resembling the Contegra conduit. Porcine pulmonary roots after decellularization were adjusted, preserving about 0.5 $\mathrm{cm}$ of pulmonary wall above the commissures and 0.3 to $0.5 \mathrm{~cm}$ of myocardial tissue below the cusps base, maintaining the valvular geometry. The valve proximal and distal ends were sutured into the pericardial tube using 5.0 Polypropylene (Figure 2).

\section{Stem cell isolation and seeding}

Three weeks before the scheduled implantation, we collected about $5 \mathrm{~cm}^{3}$ of inter-scapular adipose tissue from each animal in sterile conditions (see animal description below) and isolated ADSCs using a published collagenase-based procedure (19). The plasticity of sheep ADSCs 

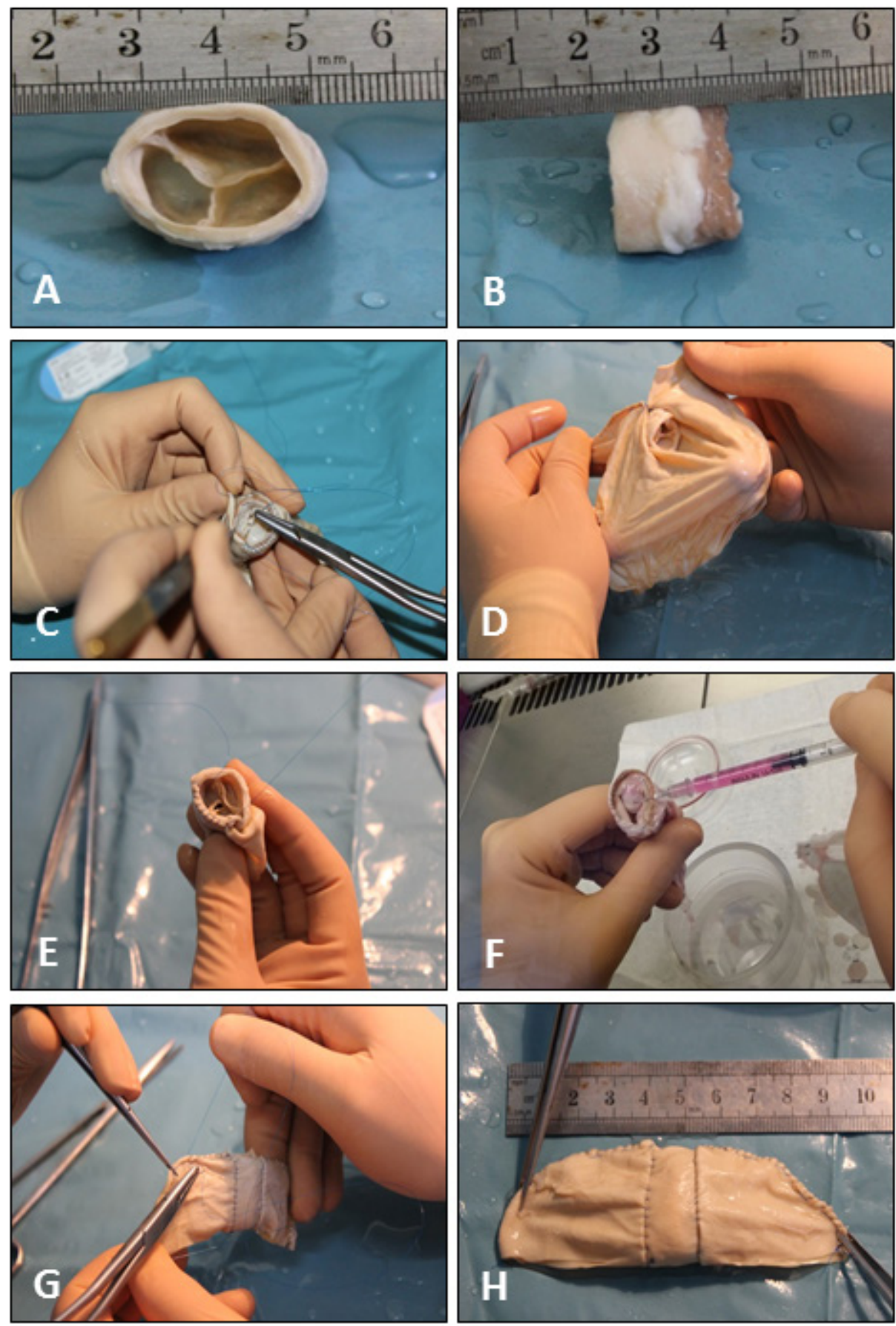

Figure 2. Procedure for valvular conduit manufacture. A,B, decellularized pulmonary root, intraluminal and lateral view; C, proximal anastomosis of the pericardium to the "valvular annulus"; D, intra-tubular aspect after the proximal anastomosis; E, distal anastomosis of the pericardium above the commissural line; F, injection of stem cells in the cusps; $\mathrm{G}$, conduit closure; $\mathrm{H}$, final aspect of the valved conduit. 
was confirmed using differentiation kits (PromoCell, Inc). Cells were propagated for up to 6 passages in the cell culture laboratory and extreme care was exercised to record the source of cells for later autologous implantation. Two days before the scheduled implantation day, the acellular valves were seeded internally with autologous ADSCs by injection of 8-10 million ADSCs in 200 ul PBS into each cusp using a 30G needle (Figure 2, F). The cell-seeded construct was immersed in DMEM/FBS medium and incubated at $37^{\circ} \mathrm{C}, 5 \% \mathrm{CO}_{2}, 90 \%$ humidity before implantation.

\section{Animals and Surgical Procedures}

All animal procedures were performed in accordance to the "Guide for the care and use of laboratory animals", published by the US NIH (NIH Publication No. 85-23, revised 1996) under a Animal Use Protocol approved by the University of Medicine and Pharmacy Targu Mures Ethical Committee (No.8/04.02.2012). Animals were placed under general anesthesia (oro-tracheal intubation and mechanical ventilation), EKG, invasive arterial pressure, central temperature and puls-oximetry monitoring, with central and peripheral venous cannulation. A left thoracotomy trough the $3^{\text {rd }}$ intercostal space provided an optimal exposure of the right ventricle outflow tract (RVOT) and pulmonary artery (PA). After systemic heparinization (1.5 $\mathrm{mg} / \mathrm{kg}$ ) and lateral clamping of the RVOT, the proximal end of the conduit was anastomosed to the right ventricle on the beating heart using a 4.0 Prolene Surjet suture; then the distal end was sutured onto the pulmonary artery in the same manner. After the complete ligation of the native pulmonary artery and unclamping of the RVOT, the conduit placed between the RVOT and the PA became a bypass route for the physiological pulmonary blood flow (Figure 3 ). Postoperatively antalgic, antibiotic, and diuretics were administered for 5 days. Anticoagulant
(Fraxiparine $2 \times 0.3 \mathrm{ml}$ ) therapy was maintained for the first 30 days and anti-aggregant treatment (Aspenter $75 \mathrm{mg}$ /day orally) for the entire length of the study.

Monthly transthoracic echography was performed under mild sedation, monitoring the valve hemodynamics, leaflet mobility and thickness, and evidence for right heart remodeling. Animals were randomly divided into two groups: Group A $(n=6)$ consisting of animals with implanted decellularized pulmonary xenografts and Group B ( $n=6)$ with implanted decellularized pulmonary xenografts seeded internally with autologous ADSCs. Animals were followed for up to 6 months. Explanted valves were analyzed by macroscopic evaluation and histology.

\section{Histological assessment}

The tissue fragments were processed according to standard histological techniques. The explanted valves were fixed in neutral formalin, embedded in paraffin, and $5 \mu \mathrm{m}$ sections were obtained and stained with Hematoxylin and Eosin. As an external control, two decellularized valves and two fresh (non-decellularized) valves were also included for histological evaluation. Additionally, one seeded valve (,time zero”) and one unseeded valve were obtained after about 30 minutes of blood flow through the valved conduit, due to intra-operatory death, unrelated to the valve itself.

\section{Results}

\section{Decellularization assessment}

Histology and DNA analysis showed that our decellularization procedure generated completely acellular cusp and arterial root tissue components. Essentially no nuclei could be found by H\&E stain and also by the more sensitive DAPI nuclear staining (Figure 1). Notably, acellular cusps exhibited large areas of void volumes (pores), where the valve cells used to 

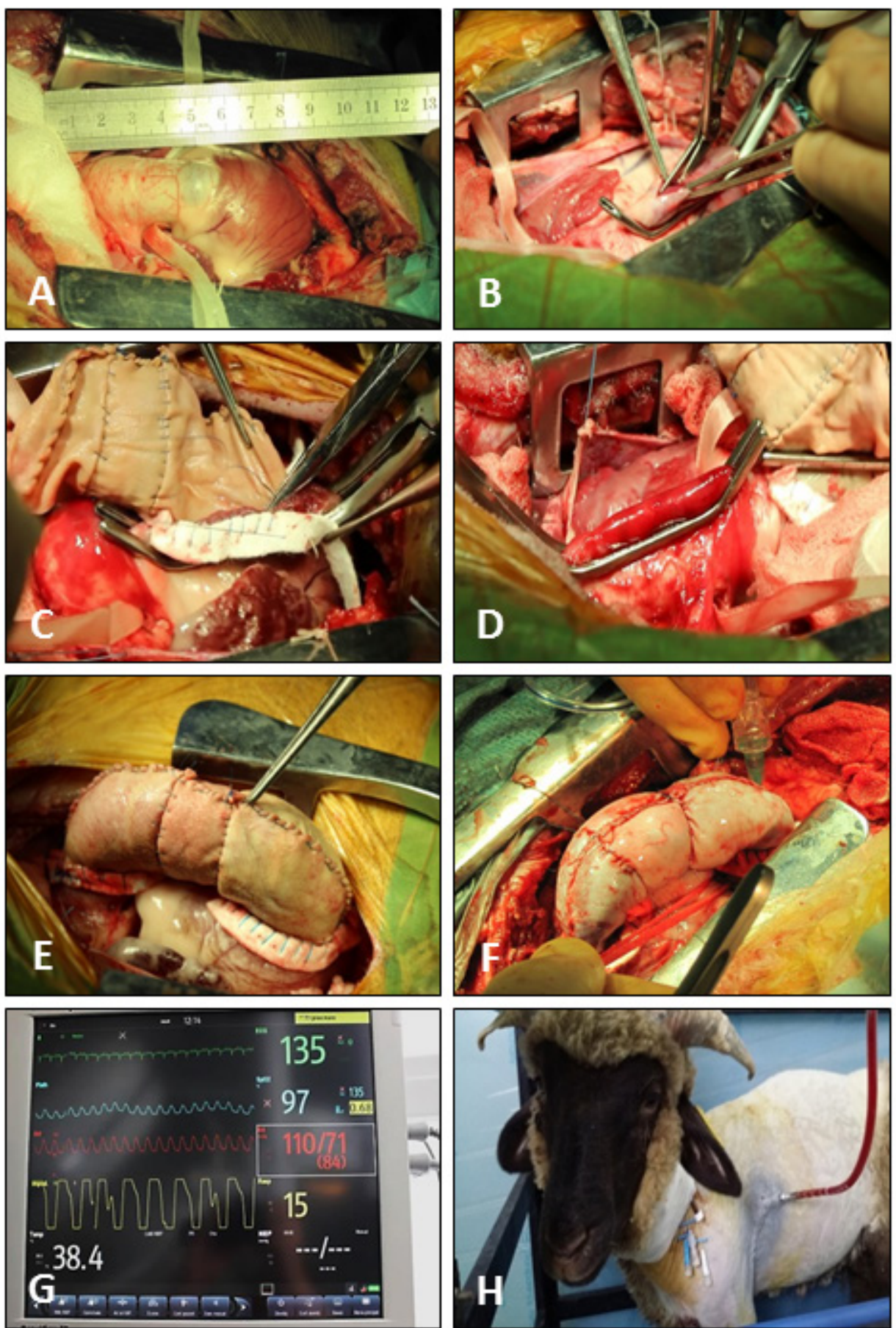

Figure 3. Surgical procedure. A, Exposure of pulmonary artery and right ventricle through lateral thoracotomy;

$\mathrm{B}$, lateral clamping of the right ventricle followed by ventriculotomy; $\mathrm{C}$, proximal end of conduit sutured to the right ventricle; D, lateral clamping of the pulmonary artery; E, final aspect, functional valvular conduit; F, invasive measurement of intra-operatory pressure; G, Peri-operatory monitoring: EKG (green), pulsoximetry (blue), invasive blood pressure (red), respiratory rate (yellow), central temperature (white); H, Post-operatory aspects: central venous catheter in the left external jugular vein, preventative thoracic drainage. 
reside before extraction. In addition, no DNA could be observed on EtBr-stained agarose gel electrophoresis.

\section{Animal evaluation and macroscopic analy- sis of explanted valves}

The early (up to 4 weeks) post-operatory evolution of all animals was favorable, with rapid recovery and without immediate complications or early deaths.

All animals (6/6) in Group A survived to 6 months and had physiologic growth without signs of pulmonary or heart failure. Echocardiographic examination revealed valve leaflets with a preserved structure, no impaired mobility and minimal regurgitation, and no inflammation or calcification.

By comparison, animals in Group B had a different evolution. After about 1 month of follow-up, animals started to present symptoms of right ventricular failure, including dyspnea, pleurisy and ascites. These symptoms were correlated with echographic aspects consisting of cusp thickening and reduced mobility, resulting in valvular insufficiency and right ventricular dilatation (Figure 4). Only two sheep survived to term (6 months), the remainder necessitating euthanasia at 1, 2, 3 and 4 months.

Upon macroscopic evaluation, fibrous tissue overgrowth was observed in all valves, covering
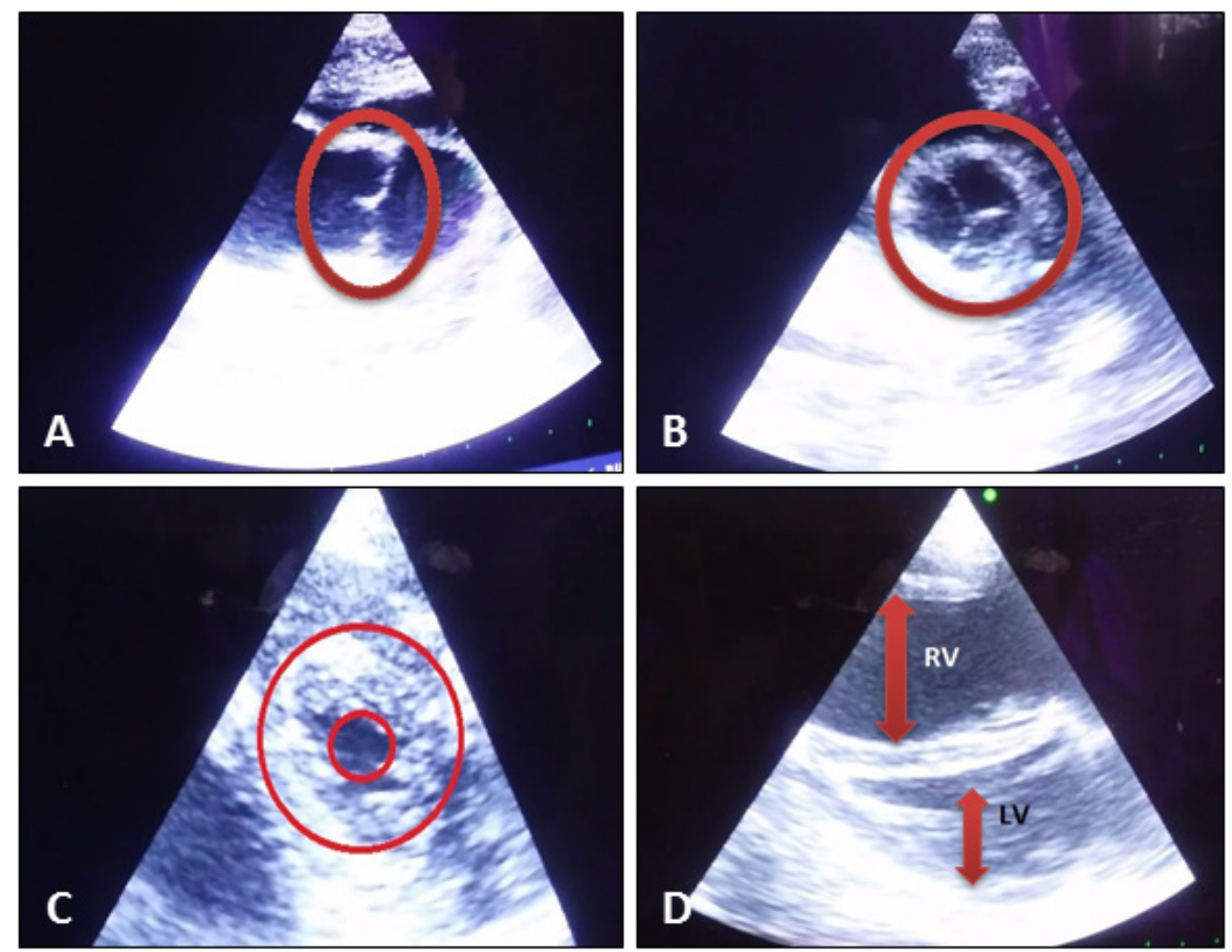

Figure 4. Representative echocardiography aspects. A, B, Group A implants on short (A) and long (B) axis: slender, thin and flexible leaflets with appropriate central coaptation, with no visible thrombi at this level; C, Group B implants on short axis: host tissue overgrowth, enclosing the cusps (the area between the circles), with reduced valvular opening (the small circle); D, Right ventricle (RV) dilatation compared with the left ventricle (LV) diameter (pathologic inversed proportion). 
both distal and proximal anastomoses, the pericardial segments and also slowly enclosing the cusps (Figure 5).

\section{Histological features of the explanted valves}

All valves explanted from Group A presented preserved leaflets integrity. Focal or diffuse fibrin deposits were noted on the valves that were exposed to blood flow for only 30 minutes (Figure 6). In Group B valves, the most notable finding was the presence of a 100-300 um thick, well developed fibrous tissue, rich in fibroblasts and connective tissue covering all surfaces (Figure 6). In most samples analyzed, the cusp tissues were still intact, but covered in fibrous tis- sue which limited their mobility. No cells of any kind could be detected in any of the cusp tissue, including lack of any seeded cells, infiltrated inflammatory cells or fibroblasts. In addition, no thrombosis occurred at the cusp surface. Calcification was absent from all cusp tissues analyzed.

\section{Discussions}

The main treatment for valvular diseases consists in their surgical replacement, with either mechanical or biological valves. Both these devices have limited life spans and are associated with bleeding risks (mechanical valves) and degeneration (biological prosthesis) (2). Heart valve tissue engineering (HVTE), the science
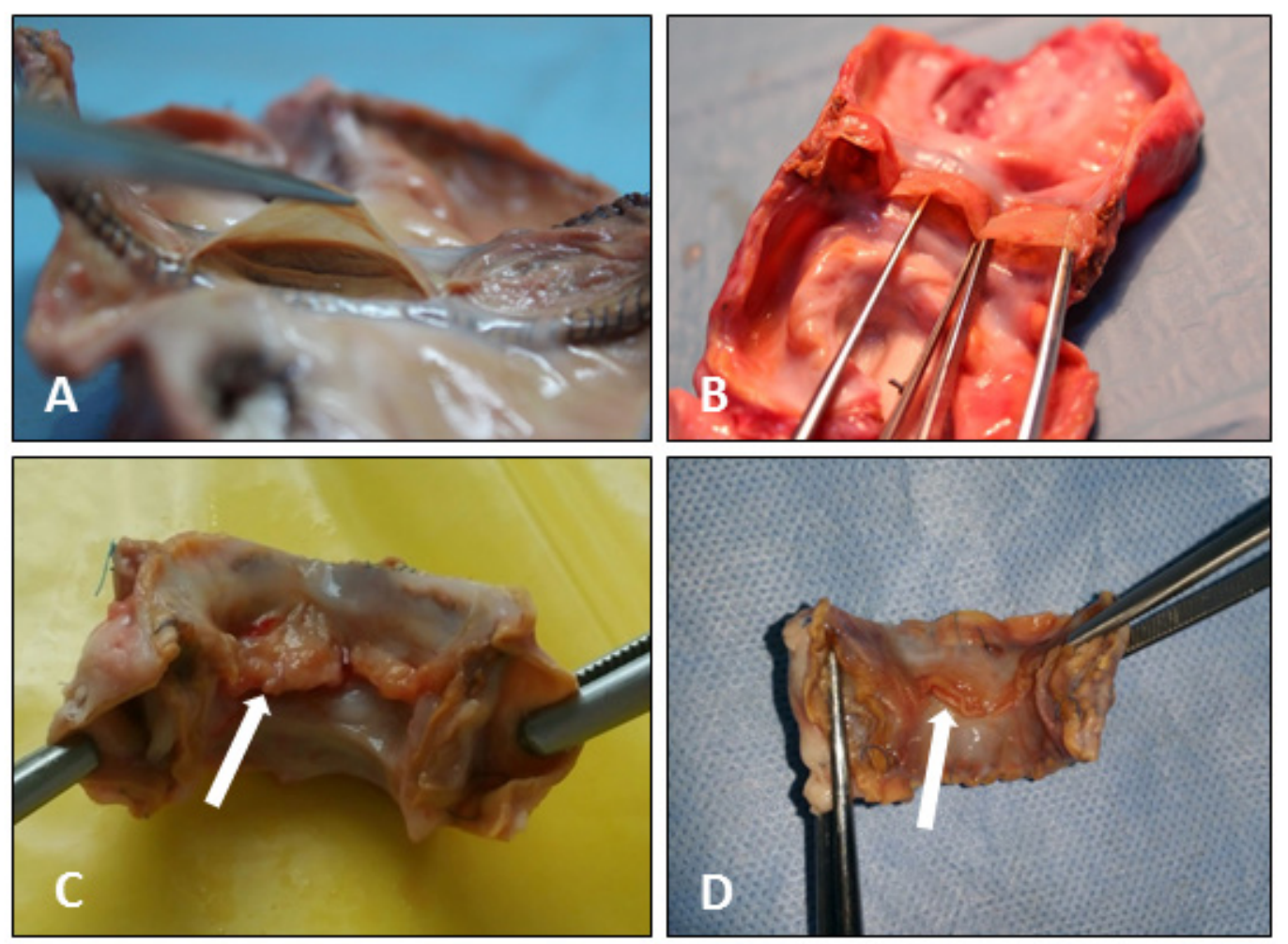

Figure 5. Macroscopic aspects of explanted valves. A, B, Group A explants after 6 months of in vivo testing: thin, smooth, flexible cusps without macroscopically visible thrombi, leaflet hematoma or calcification; C, D, Group B explants at 2 and 3 months after implantation: host tissue overgrowth covering the cusp bases. Arrows point to remnant leaflet free margins. The entire valvular apparatus was thick, with complete loss of function. 

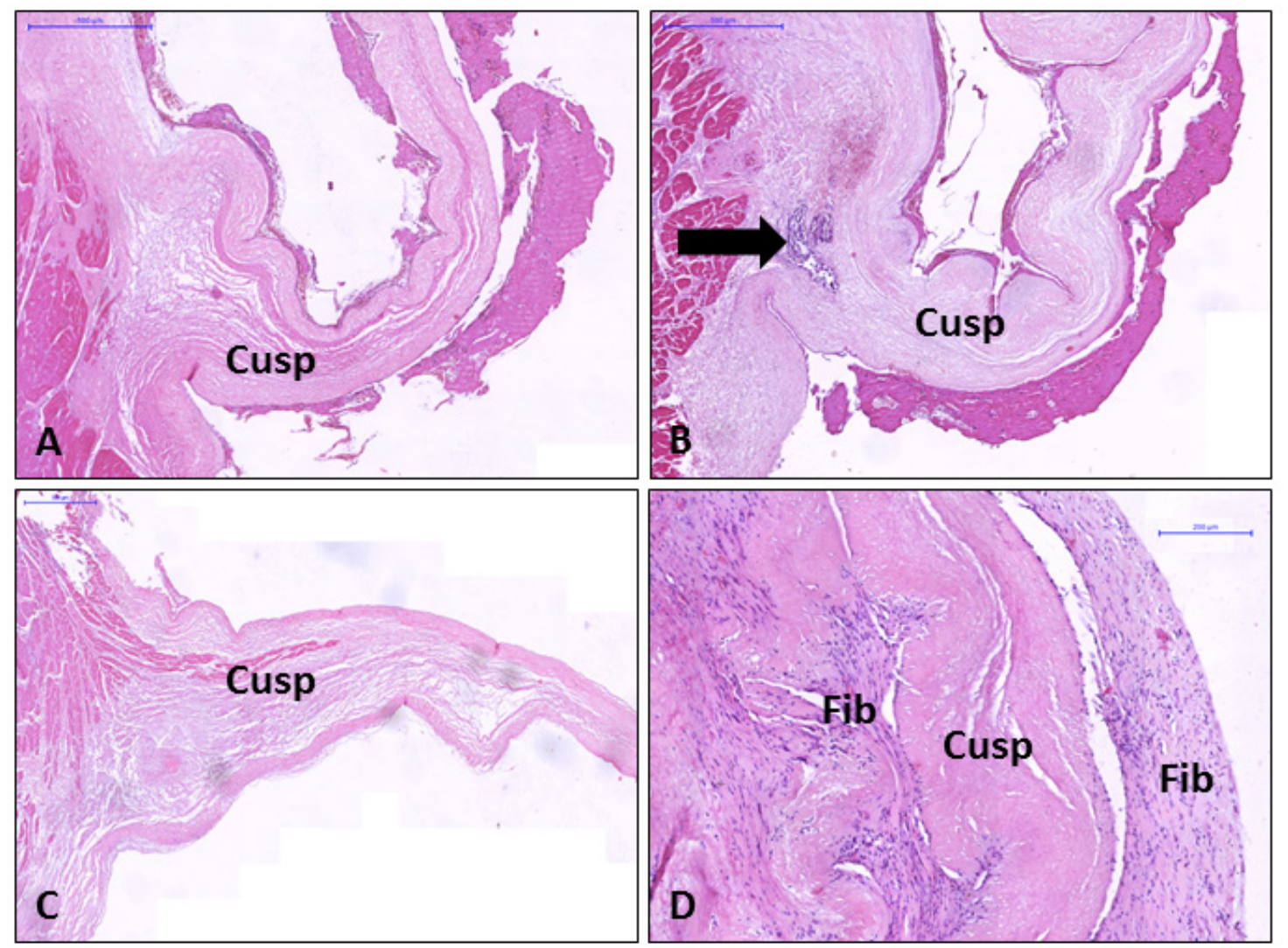

Figure 6. Representative histological aspects. A, C, valves explanted from Group A animals. B, D, valves explanted from Group B animals. A and B are specimens obtained after just 30 minutes of exposure to flowing

blood (intra-operatory death, unrelated to the implants). Arrow in (B) points to the area of injected stem cells. Note a diffuse fibrin layer on all surfaces. C, D, sections through roots explanted after 6 and 3 months, respectively. Note lack of thrombi, inflammation and calcification in both and also extensive coverage of the cusp tissue in a fibrous capsule (Fib) in (D). H\&E stain; scale bars in A, B and C are 500 um, bar in D is 200 um.

of combining scaffolds, cells and stimuli has the potential to revolutionize the field of valve surgery by providing functional, durable, and viable valves. To date, several approaches have been tested using synthetic and natural scaffolds and a variety of cells and bioreactors, but overall most approaches have not been successful on the long term when tested in animals or human patients as pulmonary or aortic implants $(2,4-6)$. At this stage of research, there are numerous aspects which still need to be studied, optimized or tested before HVTE can make an impact on clinical applications. For example, it is not yet known what the ideal scaffold properties are and whether it should be rapidly degradable, slowly degradable or not degradable at all (2, 4-6, 20). Other topics of research are cell sourcing, propagation, whether in vitro differentiation or in vitro mechanical pre-conditioning is needed before implantation, seeding methods, and optimal number of seeded cells.

\section{Rationale and hypothesis}

Based on previous experience, we hypothesized that an ideal scaffold would be stabilized acellular porcine roots seeded with autologous 
stem cells. We chose porcine valves because they closely mimic the human valve anatomy and have a long history of implantation in patients. Notably, porcine valves treated with glutaraldehyde have been implanted in millions of patients and most of them fail by calcification after 3-4 months in sheep or after 10-15 years in humans. The main mechanism of calcification is related to the presence of devitalized cells (21); therefore, acellular valves are good candidates for use as non-calcifying scaffolds. Moreover, it is well known that acellular tissues, if fully decellularized, are not immunogenic, because collagen and elastin are two proteins which have been preserved throughout evolution and thus are not different among species. For this reason, more than 1 million acellular tissues and collagen scaffolds in liquid or solid form have already been implanted in humans without any signs of immunologic rejection $(6,12)$. Therefore, acellular valves are not expected to activate the immune system (6).

To test our approach, we completely decellularized porcine pulmonary roots using detergents and enzymes and treated the matrix with PGG, which resulted in functional roots with preserved matrix and mechanical properties. Treatment with PGG, a non-cytotoxic collagen and elastin binding polyphenol reduces susceptibility to collagenase, thus increasing the durability of matrix scaffolds upon implantation $(7,15,18,22)$. In an attempt to re-cellularize the aortic roots, we isolated sheep ADSCs and seeded them into each of the three cusps by a single injection. To our knowledge this is among the first attempts to revitalize the cusp interstitium with autologous ADSCs. The injection created a single bolus of cells and we hypothesized that these cells would diffuse out and spread throughout the porous cusp interstitium and possibly differentiate into valvular interstitial cells as a response to physiological mechanical stimuli.

\section{Acellular scaffolds and their behavior in} vivo

Porcine pulmonary roots were decellularized completely, as shown by histology with DAPI and DNA analysis, the two most accepted criteria for effective decellularization (12). The valve roots were then sutured to a conduit made from acellular pericardium, to generate a valved conduit for RV-PA shunt implantation. This approach was inspired by the Contegra prosthesis used for RVOT reconstruction. We chose acellular pericardium as we have already shown that it is an ideal material for cardiac surgery (17), and valve tissue engineering (7) and being acellular, it has a very low propensity to calcify in vivo (18).

Acellular valved conduits treated with PGG were implanted in sheep and followed for up to 6 months (Group A). This has been recognized as the FDA-recommended animal model for testing new designs of mechanical valves, tissue-based bioprosthetic valves, cryopreserved homografts and biohybrid devices $(6,20,23-28)$. Although not initially developed for tissue engineering, sheep implantation continues to be the animal model of choice for testing of acellular valve scaffolds (29-34). The juvenile sheep model is accessible, reproducible, accelerates valve calcification and approximates the human anatomy.

The animals in Group A recovered rapidly from surgery without immediate complications or early deaths, and all animals survived to 6 months, without any signs of pulmonary or heart failure. Valve leaflets preserved their structure and mobility and upon explantation showed no inflammation, thrombosis or calcification. This is important, because glutaraldehyde treated porcine valves calcify heavily when implanted in juvenile sheep (21) and this pathology is associated with inflammation (35). Notably, there were no signs of immune activation or rejection pointing to the lack of immunogenicity of acellular valves. In addition, despite the complete re- 
moval of endothelium during decellularization, the exposed basal lamina of the valve and arterial tissues did not encourage long-term thrombogenesis. Overall, it appeared that stabilized acellular valves are a good alternative to the current valve replacements.

\section{Cell-seeded valves and in vivo performance}

A second group of animals were implanted with stem cell seeded acellular scaffolds. We chose ADSCs because of their ability to differentiate into valve cells when exposed to valve matrix components and mechanical stimuli $(7,16)$. ADSCs were maintained in culture and tested positively for plasticity using standard differentiation kits. Valves were seeded with autologous ADSCs and then implanted in juvenile sheep and monitored for up to 6 months. Animals in Group $\mathrm{B}$ had a different evolution from those in Group A. After about 1 month of implantation, all animals developed signs of right ventricular insufficiency and valve cusps appeared thickened and less mobile, leading to dyspnea, pleurisy, and ascites and right ventricular dilatation. The pathology progressed with time, but at different rates for different sheep. The reason for this differential pathology is not well understood. The sheep is known for its propensity to develop excessive fibrotic response to valve implants, and this reaction was considered exuberant when compared to humans (36-38). This pathology is not well understood and clearly understudied; it is not clear at this point what initiates the fibrotic reaction, what contributes to its progression and cessation and why certain implants develop very little fibrous overgrowth, while others are completely covered to their full extent. To our knowledge this is the first time that cell seeded valves are compared to their non-seeded controls.

Comparing our results with the published, we hypothesized that the presence of the injected stem cells and cell remnants possibly initiated, exacerbated, and sustained fibrous overgrowth in the RVOT. It is known that ADSCs secrete numerous cytokines and growth factors such as TGF, FGF and TNF and that the efficacy of cell therapy with ASCs is related to their paracrine effects $(39,40)$. Therefore it is possible that while in the cusps, the ADSCs have secreted pro-fibrotic agents which stimulated and accelerated the fibrous tissue overgrowth. It is not clear whether this is specific to stem cells and this aspect warrants more investigation.

\section{Potential limitations and future studies}

One important aspect which needs further investigation is to find out whether seeded cells actually survived within the valve interstitium, and whether they were not affected by the mechanical stress to which cusps are subjected each cardiac cycle. This includes bending, stretching, and extending forces which could have affected cell viability. It is possible that stem cells are vulnerable to mechanical stress and thus mechanical adaptation and pre-conditioning in vitro before implantation could be needed. In vitro experiments with seeded valves tested in bioreactors are under way in our lab. In addition, a series of experiments should be conducted with fluorescently labeled cells to evaluate their fate after implantation.

Further improvements in cell seeding procedures are also needed, replacing the single injection with methods capable of homogeneously distributing cells within the valve interstitium. Also, orthotopic implantation of valves would be the next animal model to test, since it will provide additional clinical significance. In this respect, since sheep have a tendency to fibrose over valvular implants, alternative large animal models would need to be evaluated.

\section{Conclusions}

Acellular stabilized pulmonary roots are excellent valve replacement alternatives. They 
exhibit adequate hemodynamics and the matrix scaffold is non-immunogenic, non-thrombogenic and non-calcifying in an animal model which typically induces severe degeneration of tissue valves. Notably, cell removal creates pores which could serve as sites for re-cellularization. Seeding these scaffolds with autologous ADSCs was not conducive to tissue regeneration and at least in the current sheep model, the presence of stem cells was associated with extensive fibrotic reactions from the host. Further basic and pre-clinical studies are needed to fully harness the potential of stem cells in heart valve tissue engineering.

\section{Acknowledgments}

This project was funded in part by a grant from the Romanian National Authority for Scientific Research, CNCS-UEFISCDI, project number PNII-ID-PCCE-2011-2-0036, by a grant from NHLBI of the National Institutes of Health, USA under award number RO1HL093399, and by a grant from NIGMS of the National Institutes of Health, USA under award number 5P20GM103444-07.
Abbreviations
ADSCs $=$ adipose derived stem cells
$\mathrm{RV}=$ right ventricle
$\mathrm{PA}=$ pulmonary artery
TEHV = tissue engineered heart valve
PGG $=$ penta-galloyl glucose
$\mathrm{H} \& \mathrm{E}=$ Hematoxylin and Eosin
$\mathrm{RVOT}=$ right ventricle outflow tract

\section{References}

1. Duran CG. [the Behavior of Aortic Valve Homografts in Man and Animals]. Coeur Med Interne. 1964 Jul;64:301-5.

2. Simionescu DT, Chen J, Jaeggli M, Wang B, Liao J. Form Follows Function: Advances in Trilayered Structure Replication for Aortic Heart Valve Tissue Engi- neering. J Healthc Eng. 2012 Jun;3(2):179-202. DOI: 10.1260/2040-2295.3.2.179

3. Zilla P, Human P, Bezuidenhout D. Bioprosthetic heart valves: the need for a quantum leap. Biotechnol Appl Biochem. 2004 Aug;40(Pt 1):57-66.

4. Sohier J, Carubelli I, Sarathchandra P, Latif N, Chester $\mathrm{AH}$, Yacoub MH. The potential of anisotropic matrices as substrate for heart valve engineering. Biomaterials. 2014 Feb;35(6):1833-44. DOI: 10.1016/j.biomaterials.2013.10.061

5. Weber B, Dijkman PE, Scherman J, Sanders B, Emmert MY, Grunenfelder J, et al. Off-the-shelf human decellularized tissue-engineered heart valves in a non-human primate model. Biomaterials. 2013 Oct;34(30):726980. DOI: 10.1016/j.biomaterials.2013.04.059

6. Tudorache I, Calistru A, Baraki H, Meyer T, Hoffler K, Sarikouch S, et al. Orthotopic replacement of aortic heart valves with tissue-engineered grafts. Tissue Eng Part A. 2013 Aug;19(15-16):1686-94. DOI: 10.1089/ ten.tea.2012.0074

7. Tedder ME, Simionescu A, Chen J, Liao J, Simionescu DT. Assembly and testing of stem cell-seeded layered collagen constructs for heart valve tissue engineering. Tissue Eng Part A. 2011 Jan;17(1-2):25-36. DOI: 10.1089/ten.tea.2010.0138

8. $\mathrm{Ku} \mathrm{CH}$, Johnson PH, Batten P, Sarathchandra P, Chambers RC, Taylor PM, et al. Collagen synthesis by mesenchymal stem cells and aortic valve interstitial cells in response to mechanical stretch. Cardiovasc Res. 2006 Aug 1;71(3):548-56. DOI: 10.1016/j.cardiores.2006.03.022

9. Shinoka T, Ma PX, Shum-Tim D, Breuer CK, Cusick RA, Zund G, et al. Tissue-engineered heart valves. Autologous valve leaflet replacement study in a lamb model. Circulation. 1996 Nov 1;94(9 Suppl):II164-8.

10. Sierad LN, Simionescu A, Albers C, Chen J, Maivelett J, Tedder ME, et al. Design and Testing of a Pulsatile Conditioning System for Dynamic Endothelialization of Polyphenol-Stabilized Tissue Engineered Heart Valves. Cardiovasc Eng Technol. 2010 Jun;1(2):13853. DOI: $10.1007 / \mathrm{s} 13239-010-0014-6$

11. Mercuri JJ, Patnaik S, Dion G, Gill SS, Liao J, Simionescu DT. Regenerative potential of decellularized porcine nucleus pulposus hydrogel scaffolds: stem cell differentiation, matrix remodeling, and biocompatibility studies. Tissue Eng Part A. 2013 Apr;19(7-8):95266. DOI: 10.1089/ten.tea.2012.0088 
12. Badylak SF. Decellularized allogeneic and xenogeneic tissue as a bioscaffold for regenerative medicine: factors that influence the host response. Ann Biomed Eng. 2014 Jul;42(7):1517-27. DOI: 10.1007/s10439-0130963-7

13. Isenburg JC, Simionescu DT, Starcher BC, Vyavahare NR. Elastin stabilization for treatment of abdominal aortic aneurysms. Circulation. 2007 Apr 3;115(13):172937. DOI: $10.1161 /$ CIRCULATIONAHA.106.672873

14. Chow JP, Simionescu DT, Warner H, Wang B, Patnaik SS, Liao J, et al. Mitigation of diabetes-related complications in implanted collagen and elastin scaffolds using matrix-binding polyphenol. Biomaterials. 2013 Jan;34(3):685-95. DOI: 10.1016/j.biomaterials.2012.09.081

15. Pennel T, Fercana G, Bezuidenhout D, Simionescu A, Chuang TH, Zilla P, et al. The performance of crosslinked acellular arterial scaffolds as vascular grafts; pre-clinical testing in direct and isolation loop circulatory models. Biomaterials. 2014 Aug;35(24):6311-22. DOI: $10.1016 /$ j.biomaterials.2014.04.062

16. Colazzo F, Alrashed F, Saratchandra P, Carubelli I, Chester AH, Yacoub MH, et al. Shear stress and VEGF enhance endothelial differentiation of human adipose-derived stem cells. Growth Factors. 2014 Oct;32(5):13949. DOI: $10.3109 / 08977194.2014 .945642$

17. Deac RF, Simionescu D, Deac D. New evolution in mitral physiology and surgery: mitral stentless pericardial valve. Ann Thorac Surg. 1995 Aug;60(2 Suppl):S433-8. DOI: 10.1016/0003-4975(95)00303-3

18. Tedder ME, Liao J, Weed B, Stabler C, Zhang H, Simionescu A, et al. Stabilized collagen scaffolds for heart valve tissue engineering. Tissue Eng Part A. 2009 Jun;15(6):1257-68. DOI: 10.1089/ten.tea.2008.0263

19. Gimble J, Guilak F. Adipose-derived adult stem cells: isolation, characterization, and differentiation potential. Cytotherapy. 2003;5(5):362-9. DOI: 10.1080/14653240310003026

20. Dijkman PE, Driessen-Mol A, Frese L, Hoerstrup SP, Baaijens FP. Decellularized homologous tissue-engineered heart valves as off-the-shelf alternatives to xenoand homografts. Biomaterials. 2012 Jun;33(18):454554. DOI: 10.1016/j.biomaterials.2012.03.015

21. Schoen FJ, Levy RJ. Pathology of substitute heart valves: new concepts and developments. J Card Surg. 1994 Mar;9(2 Suppl):222-7. DOI: 10.1111/j.15408191.1994.tb00932.x
22. Chuang TH, Stabler C, Simionescu A, Simionescu DT. Polyphenol-stabilized tubular elastin scaffolds for tissue engineered vascular grafts. Tissue Eng Part A. 2009 Oct;15(10):2837-51. DOI: 10.1089/ten.tea.2008.0394

23. Paniagua Gutierrez JR, Berry H, Korossis S, Mirsadraee S, Lopes SV, da Costa F, et al. Regenerative potential of low-concentration SDS-decellularized porcine aortic valved conduits in vivo. Tissue Eng Part A. 2015 Jan;21(1-2):332-42. DOI: 10.1089/ten.tea.2014.0003

24. Syedain ZH, Meier LA, Reimer JM, Tranquillo RT. Tubular heart valves from decellularized engineered tissue. Ann Biomed Eng. 2013 Dec;41(12):2645-54. DOI: 10.1007/s10439-013-0872-9

25. Lisy M, Pennecke J, Brockbank KG, Fritze O, Schleicher M, Schenke-Layland K, et al. The performance of ice-free cryopreserved heart valve allografts in an orthotopic pulmonary sheep model. Biomaterials. 2010 Jul;31(20):5306-11. DOI: 10.1016/j.biomaterials.2010.03.038

26. Hopkins RA, Jones AL, Wolfinbarger L, Moore MA, Bert AA, Lofland GK. Decellularization reduces calcification while improving both durability and 1-year functional results of pulmonary homograft valves in juvenile sheep. J Thorac Cardiovasc Surg. 2009 Apr;137(4):907-13, 13e1-4.

27. Shinoka T, Breuer CK, Tanel RE, Zund G, Miura T, Ma $\mathrm{PX}$, et al. Tissue engineering heart valves: valve leaflet replacement study in a lamb model. Ann Thorac Surg. 1995 Dec;60(6 Suppl):S513-6. DOI: 10.1016/00034975(95)00733-4

28. Hopkins RA, Bert AA, Hilbert SL, Quinn RW, Brasky KM, Drake WB, et al. Bioengineered human and allogeneic pulmonary valve conduits chronically implanted orthotopically in baboons: hemodynamic performance and immunologic consequences. J Thorac Cardiovasc Surg. 2013 Apr;145(4):1098-107. DOI: 10.1016/j. jtcvs.2012.06.024

29. Khorramirouz R, Sabetkish S, Akbarzadeh A, Muhammadnejad A, Heidari R, Kajbafzadeh AM. Effect of three decellularisation protocols on the mechanical behaviour and structural properties of sheep aortic valve conduits. Adv Med Sci. 2014 Sep;59(2):299-307. DOI: 10.1016/j.advms.2014.08.004

30. Fallon AM, Goodchild TT, Cox JL, Matheny RG. In vivo remodeling potential of a novel bioprosthetic tricuspid valve in an ovine model. J Thorac Cardiovasc Surg. 2014 Jul;148(1):333-40 e1. 
31. Lichtenberg A, Cebotari S, Tudorache I, Sturz G, Winterhalter M, Hilfiker A, et al. Flow-dependent re-endothelialization of tissue-engineered heart valves. J Heart Valve Dis. 2006 Mar;15(2):287-93; discussion 93-4.

32. Dohmen PM, Ozaki S, Yperman J, Flameng W, Konertz W. Lack of calcification of tissue engineered heart valves in juvenile sheep. Semin Thorac Cardiovasc Surg. 2001 Oct;13(4 Suppl 1):93-8.

33. Goldstein S, Clarke DR, Walsh SP, Black KS, O'Brien MF. Transpecies heart valve transplant: advanced studies of a bioengineered xeno-autograft. Ann Thorac Surg. 2000 Dec;70(6):1962-9. DOI: 10.1016/S00034975(00)01812-9

34. O'Brien MF, Goldstein S, Walsh S, Black KS, Elkins R, Clarke D. The SynerGraft valve: a new acellular (nonglutaraldehyde-fixed) tissue heart valve for autologous recellularization first experimental studies before clinical implantation. Semin Thorac Cardiovasc Surg. 1999 Oct;11(4 Suppl 1):194-200.

35. Simionescu A, Simionescu D, Deac R. Biochemical pathways of tissue degeneration in bioprosthetic cardiac valves. The role of matrix metalloproteinases. ASAIO J. 1996 Sep-Oct;42(5):M561-7. DOI: 10.1097/00002480-
199609000-00049

36. Schoen FJ. Pathologic findings in explanted clinical bioprosthetic valves fabricated from photooxidized bovine pericardium. J Heart Valve Dis. 1998 Mar;7(2):174-9.

37. Hilbert SL, Yanagida R, Souza J, Wolfinbarger L, Jones AL, Krueger P, et al. Prototype anionic detergent technique used to decellularize allograft valve conduits evaluated in the right ventricular outflow tract in sheep. J Heart Valve Dis. 2004 Sep;13(5):831-40.

38. Hopkins RA. Right ventricular outflow tract reconstructions: the role of valves in the viable allograft era. Ann Thorac Surg. 1988 Jun;45(6):593-4. DOI: 10.1016/ S0003-4975(10)64757-1

39. Semon JA, Maness C, Zhang X, Sharkey SA, Beuttler MM, Shah FS, et al. Comparison of human adult stem cells from adipose tissue and bone marrow in the treatment of experimental autoimmune encephalomyelitis. Stem Cell Res Ther. 2014;5(1):2. DOI: 10.1186/scrt391

40. Gimble JM, Bunnell BA, Frazier T, Rowan B, Shah F, Thomas-Porch C, et al. Adipose-derived stromal/stem cells: a primer. Organogenesis. 2013 Jan-Mar;9(1):3-10. DOI: $10.4161 /$ org. 24279 
